$(1975)$

10. J. S. Dunning, Ph.D. Thesis, University of California, Los Angeles, CA (1971)

11. J. A. Trainham, Ph.D. Thesis, University of California, Los Angeles, CA (1979).

12. P. De Vidts Sabelle, Ph.D. Thesis, Texas A\&M University, College Station, TX (1995).

13. J. S. Newman, Electrochemical Systems, 2nd ed., Prentice Hall, Englewood Cliffs, NJ (1991)

14. H. S. Fogler, Elements of Chemical Reaction Engineering, 2nd ed., Prentice Hall, Englewood Cliffs, NJ (1992).
15. G. F. Froment and K. B. Bischoff, Chemical Reactor Analysis and Design, 2nd ed., John Wiley \& Sons, Inc., New York (1990).

16. $\mathrm{R} . \mathrm{E}$ Meredith and C. W. Tobias, in Advances in Electrochemistry and Electrochemical Engineering, Vol. 2, C. W. Tobias, Editor, pp. 15-47, Interscience Publishers, New York (1962)

17. R. B. Bird, W. E. Stewart, and E. N. Lightfoot, Transport Phenomena, John Wiley \& Sons, Inc., New York (1960).

18. P. De Vidts, J. Delgado, and R. E. White, This Journal, 143, 3223 (1996).

\title{
Oxide Film Formation on a Microcrystalline Al Alloy in Sulfuric Acid
}

\author{
S. C. Thomas* and V. I. Birss* \\ Department of Chemistry, The University of Calgary, Calgary, Alberta, Canada T2N 1N4
}

\section{ABSTRACT}

The differences in the electrochemical behavior of a rapidly solidified, two-phase (matrix and dispersoid) Al-based alloy containing Fe, V, and Si (FVS0812 alloy) and the bulk form of its matrix and dispersoid phases were investigated in sulfuric acid. FVS0812 exhibited generally higher electrochemical activity than the matrix material due to the presence of the very active dispersoid phase in the alloy. Impedance studies indicated that the properties of thin films formed on the FVS0812 and matrix substrates during only $5 \mathrm{~min}$ of anodization are similar, whereas the film formed on the alloy during $2.5 \mathrm{~h}$ of anodization was substantially less resistive and contained a thinner and/or damaged underlying barrier oxide compared to a comparable film formed on the matrix. Compared to the classical structure of porous Al oxide films with underlying barrier oxide, the oxide film on FVS0812, as seen by TEM, was thinner, with an intermittent barrier oxide underlying a porous oxide of contorted morphology. Evidence is seen for the loss of dispersoids from the oxide film, leaving voids throughout its structure, perhaps the reason for its lack of physical adherence and its limiting thickness.

\section{Introduction}

A recent advance in both the science and technology of metallurgy has been the application of rapid solidification techniques to $\mathrm{Al}$ alloy production resulting in alloys with structures and enhanced properties that are unobtainable by conventional casting methods. ${ }^{1,2}$ The alloy under research, designated as FVS0812 by its developer, Allied Signal Incorporated, is a microcrystalline Al-based alloy which has been rapidly solidified by planar flow casting. Table I summarizes the atomic and weight percentages of the elemental components of alloy FVS0812, which contains $\mathrm{Fe}, \mathrm{V}$, and $\mathrm{Si}$ in addition to $\mathrm{Al}^{3} \mathrm{As}$ is characteristic for rapidly solidified Al-Fe-V-Si alloys, the microstructure of alloy FVS0812 consists of very fine, nearly spherical, intermetallic "dispersoids" uniformly distributed throughout a matrix phase. ${ }^{4}$ The microcrystalline matrix grain size typically varies from 0.5 to $2 \mu \mathrm{m}$ in diam. ${ }^{5}$ The matrix composition is primarily $\mathrm{Al}$ supersaturated with $\mathrm{Fe}[\mathrm{c} a .0 .5$ atom percent $(\mathrm{a} / \mathrm{o})]$ and $\mathrm{Si}(\mathrm{ca} .0 .1 \mathrm{a} / \mathrm{o})$. $^{3,6}$ The nanosized dispersoids, of nominal composition of $\mathrm{Al}_{13}(\mathrm{Fe}, \mathrm{V})_{3} \mathrm{Si}$, are $0.05 \pm$ $0.01 \mu \mathrm{m}$ in diameter and occupy $c a .27$ volume percent $(\mathrm{v} / \mathrm{o})$ of the alloy. ${ }^{4,7-9}$

In practice, it was known that significant difficulties exist in forming an adherent and sufficiently thick, porous oxide film on the alloy surface using regular anodizing methods. ${ }^{10}$ This was verified by scanning electron microscopy which showed that, in contrast to a conven-

* Electrochemical Society Active Member.

Table I. Composition of alloy FVS0812.

\begin{tabular}{lcc}
\hline Element & Atomic percent & Weight percent \\
\hline $\mathrm{Al}$ & 93.2 & 88.5 \\
$\mathrm{Fe}$ & 4.3 & 8.5 \\
$\mathrm{~V}$ & 0.8 & 1.3 \\
$\mathrm{Si}$ & 1.7 & 1.7
\end{tabular}

tional Al alloy, such as AA-6061, at which anodizing yielded a film of ca. $25 \mu \mathrm{m}$, the oxide film formed on the FVS0812 alloy surface under identical conditions resulted in a corresponding thickness of $c a .3 .4 \mu \mathrm{m}$, as shown in Fig. $1{ }^{11}$ Moreover, this oxide contained damaged segments and could be removed relatively easily. An oxide thickness of $2.5 \mu \mathrm{m}$ is considered to be adequate for general corrosion resistance, but the film should be at least 25 $\mu \mathrm{m}$ thick to protect the substrate against abrasion. ${ }^{12}$ Thus, the thin oxide film formed on FVS0812 provided inadequate abrasion resistance.

A search of the literature indicates that growth of anodic films on Al alloys containing phases of differing reactivity is extremely dependent on the intermetallic phase. The behavior of intermetallic compounds during anodizing in sulfuric acid has been generally classified into three categories, ${ }^{13}$ those intermetallics which are unchanged and incorporated into oxide films, those which are oxidized and incorporated or dissolved at a rate slower than the surrounding Al matrix, and those which are oxidized and incorporated or dissolved at a rate faster than $\mathrm{Al}$. In addition, particle size is an important factor as the extent of oxidation of the intermetallic particles will decrease with increase in size. Thus, the variability in size and distribution of intermetallic particles within the alloy as well as the anodizing conditions can explain disagreement in the literature for the seemingly same material. For example, various studies of the anodization of $\mathrm{Al}$ alloys containing dispersed $\mathrm{Al}_{3} \mathrm{Fe}$ in sulfuric acid have indicated that the discrete intermetallic particles fall out or pass into the oxide film unchanged, and form a porous oxide film with an interlying barrier layer. ${ }^{14,15}$

Al alloys supporting oxide films with a range of morphologies have been reported. For example, anodization of a rapidly solidified $\mathrm{Al}-10 \%$ Si alloy in phosphoric acid resulted in the development of a regular fine featured porous anodic film above the $\mathrm{Al}$ matrix and a Si product which grew upward from the substrate and then spread laterally parallel to the alloy/film interface. ${ }^{16}$ Therefore it 


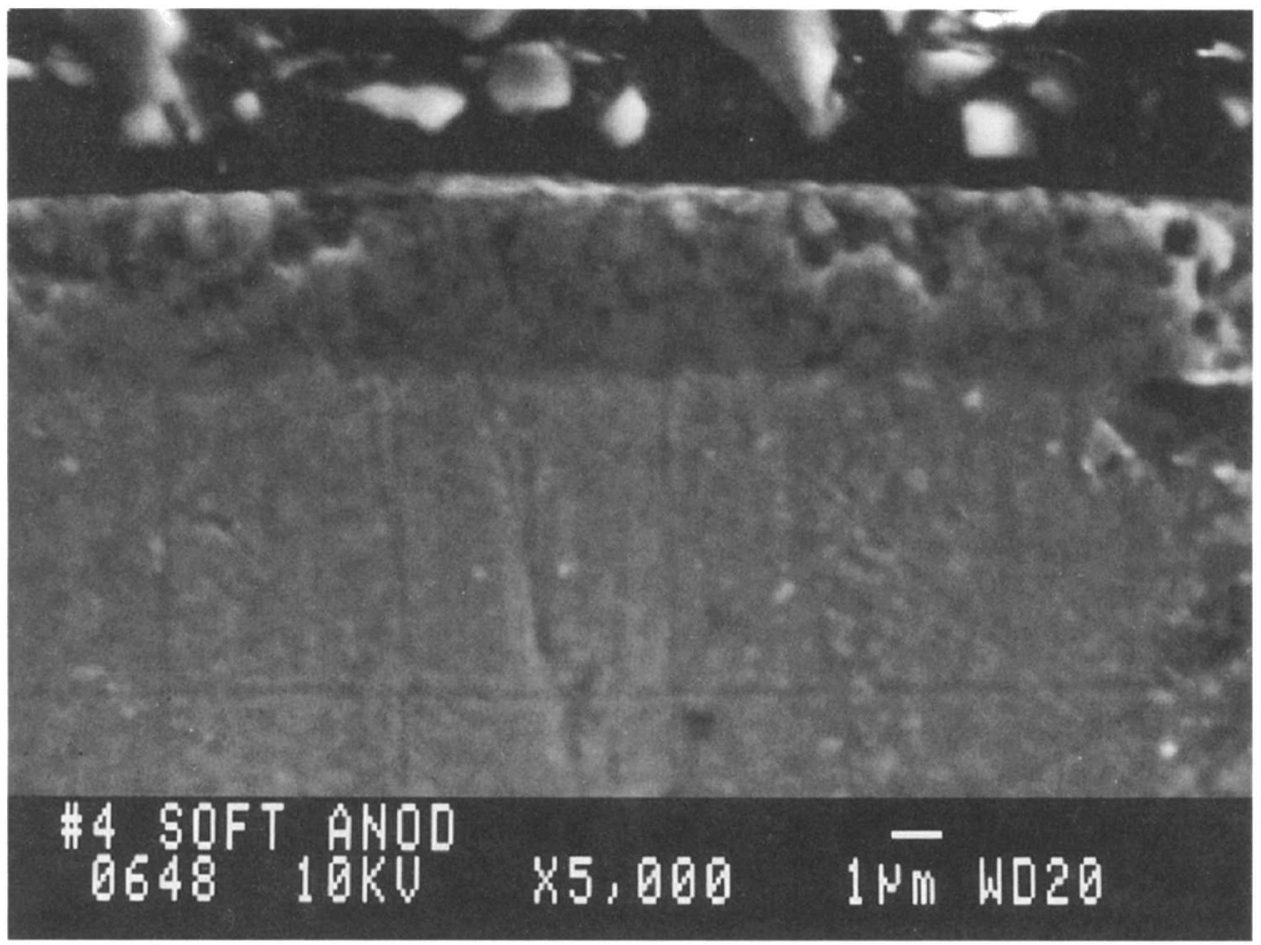

Fig. 1. Reprinted with permission." Scanning electron micrographs of cross section of FVS0812 anodized in $21^{\circ} \mathrm{C}, 1.8$ $\mathrm{mol} /$ liter sulfuric acid at $19 \mathrm{~V}$ for $20 \mathrm{~min}$. Metal on bottom, oxide in center, resin on top.

is to be expected that the FVS0812 alloy under study here might yield different anodic oxide film properties than either pure $\mathrm{Al}$ or other types of $\mathrm{Al}$ alloys.

The overall goal of this research project was to confirm the observations seen in practice and to attempt to understand the reasons for the like FVS0812 alloy's inability to form a strong, adherent, thick, porous oxide film. The primary objective of the work reported in this paper was to examine the differences in the properties of porous oxide films formed on alloy FVS0812 and $\mathrm{Al}$ in room temperature $2.0 \mathrm{~mol} /$ liter sulfuric acid, using temperature and solution conditions similar to those under which regular anodizing is performed. ${ }^{10}$ To accomplish this, a comparison of the electrochemical behavior of four substrates, alloy FVS0812, the bulk form of the matrix component of the alloy, the bulk form of the dispersoid component of the alloy, and pure $\mathrm{Al}$, was carried out.

\section{Experimental}

Electrodes and cells.-The working electrodes (WE) employed in this study included a rod of the extruded form of alloy FVS0812 (geometric area of exposed surface $c a$. $\left.0.27 \mathrm{~cm}^{2}\right)$, a pure polycrystalline $\mathrm{Al} \operatorname{rod}\left(\mathrm{ca} .0 .33 \mathrm{~cm}^{2}\right)$, material considered to be equivalent in composition to the matrix phase of the alloy and referred to as "matrix" (rod ca. $0.20 \mathrm{~cm}^{2}$ ), and material considered to be equivalent in composition to the intermetallic phase of the alloy and referred to as "dispersoid" (chip, ca. $0.25 \mathrm{~cm}^{2}$ ). This dispersoid material was formed by melt spinning an alloy of the appropriate composition into rapidly solidified flakes, grinding the flakes into a powder, and compacting the powder to form the bulk dispersoid. ${ }^{17}$ The pure $\mathrm{Al}$, FVS0812 alloy, matrix rods, and a small piece of the dispersoid were coated with inert resin (Scandia) leaving only the cross-sectional face exposed. All current densities $(i)$, impedances $(Z)$, resistances $(R)$, and capacitances $(C)$ are reported with respect to the geometric surface area in this paper.

The customary method for the surface preparation of the dispersoid consisted of polishing with 600 grit $\mathrm{SiC}$ paper. A multispeed machine lathe was used to obtain fresh surfaces of the pure Al (1000 rpm), matrix (1000 rpm), and FVS0812 (2000 rpm). For all electrodes, the new surface was rinsed with triply distilled water, ultrasonically cleaned in ethanol for $c a .10 \mathrm{~min}$, and again rinsed with triply distilled water before immersion in solution.
For the majority of the work, the cell arrangement consisted of a three-compartment glass cell with a large area Pt gauze counterelectrode (CE) separated from the WE compartment by a porous glass frit. A side port was utilized to introduce the WE horizontally into its compartment to allow gas bubbles to escape readily from the surface. The reference electrode (RE) was connected to the WE compartment by a Luggin capillary. The RE used for work with $2.0 \mathrm{~mol} / \mathrm{liter}$ sulfuric acid was the reversible hydrogen electrode (RHE). For work involving electrochemical impedance spectroscopy (EIS) using a neutral boric acid/sodium borate solution, a saturated calomel electrode (SCE) was utilized as the RE. In order to reduce phase shift errors at high frequencies, due to the high ohmic RE system, a fourth electrode, a smooth Pt wire, was placed in the WE compartment and connected to the $\mathrm{RE}$ via a $6.8 \mu \mathrm{F}$ capacitor. For work at constant cell potentials, the WE was inserted into the cell via the side port and a Pt $\mathrm{CE}$ was positioned directly in the WE compartment.

Electrochemical instrumentation.-Experiments were carried out utilizing standard three-electrode circuitry. An EG\&G PAR 173 potentiostat/galvanostat combined with an EG\&G 175 function generator was most commonly employed. The electrochemical data were plotted on a Hewlett Packard 7045B X/Y recorder. A Kepco power supply was used for potentiostatic work while the current/ time transients were plotted on a linear strip chart recorder. A Solartron Schlumberger $1255 \mathrm{HF}$ frequency response analyzer connected to a Solartron Schlumberger 1286 electrochemical interface was used for impedance measurements, carried out at $-0.14 \mathrm{~V}$ (SCE) in neutral solution, using a constant perturbating signal amplitude of ca. $5 \mathrm{mV}_{\text {rms }}$ over a typical frequency range of $10^{1}$ to $10^{5} \mathrm{~Hz}$ The data were collected using Z-PLOT software by Scribner Associates and analyzed with EQUIVALENT CIRCUIT Version 4.51 software by Boukamp, University of Twente. Best fit equivalent circuits, modeling each substrate and oxide film, were established based on the lowest value of the $\chi^{2}$ error, and on reasonable, low error values of the circuit components.

Solutions and solution analysis. $-2.0 \mathrm{~mol}$ liter $^{-1}$ sulfuric acid was used to oxidize the substrates. The neutral solution used for EIS measurements was 0.5 mol liter $^{-1}$ boric acid/0.025 mol liter ${ }^{-1}$ sodium borate, a buffer solution of $\mathrm{pH}$ 7.0. All solutions were prepared with A.C.S. reagent 
grade chemicals and triply distilled water. Solutions were constantly stirred and deaerated by bubbling argon gas through the solution before and during electrochemical experiments. The solution was controlled at $20 \pm 2^{\circ} \mathrm{C}$.

Solutions used in the electrochemical experiments, ca. $30 \mathrm{ml}$ in volume, were analyzed to establish the extent of metal dissolution by using either an ARL $35000 \mathrm{C}$ or ARL 3510 inductively coupled plasma-atomic emission spectroscopy (ICP-AES) instrument.

Surface analysis.-Sections of selected surfaces were prepared by ultramicrotomy using either an RMC MT 6000 or a Reichert/Jung Ultracut E ultramicrotome. Specimens were embedded in rectangular prism-shaped silicon molds using Spurr's low viscosity embedding resin. Residual air was removed from the encapsulated specimen by evacuation before curing at $60^{\circ} \mathrm{C}$ under vacuum for greater than $8 \mathrm{~h}$. The tip of the specimen block was reduced to a flat trapezoidal shape with dimensions of ca. $1 \mathrm{~mm} / \mathrm{side}$ by mechanically polishing, trimming with a razor blade, and slicing with a glass knife. Thin sections of the sample containing the metal/metal oxide/resin interfaces were sliced from the sample tip using a Jumdi diamond knife with a cutting angle of $45^{\circ}$ and a clearance angle of $4^{\circ}$. Cutting speeds and the thickness of sections varied, but typical values were $1.5 \mathrm{~mm} / \mathrm{s}$ and $30 \mathrm{~nm}$, respectively. The thin sections were retrieved from the water bath onto 200 mesh $\mathrm{Cu}$ grids.

The ultramicrotomed sections were examined with either a Hitachi $\mathrm{H} 7000$, Hitachi $\mathrm{H} 9000$, or Philips 400 transmission electron microscope (TEM) using accelerating voltages from 75 to $300 \mathrm{kV}$. The composition of the ultramicrotomed sections was determined by energy dispersive $\mathrm{x}$-ray analysis (EDX) using an Oxford Instruments Link AN 10000 attached to the Hitachi H 9000 TEM.

\section{Results and Discussion}

General electrochemical behavior.-As the majority of the published work by others with $\mathrm{Al}$ and its alloys has been performed under galvanostatic or potentiostatic conditions in the past, the current passed at constant applied potential was monitored to permit a comparison with literature results as well as to serve as a check on the subsequent potentiodynamic work. Figure 2 illustrates the typical current density transients $(i / t)$ obtained while the substrates were held at $+10 \mathrm{~V} v s$. a Pt CE in $2.0 \mathrm{~mol} / \mathrm{liter}$ sulfuric acid after a potential step from open circuit. The $i / t$ transient obtained for the matrix at constant potential

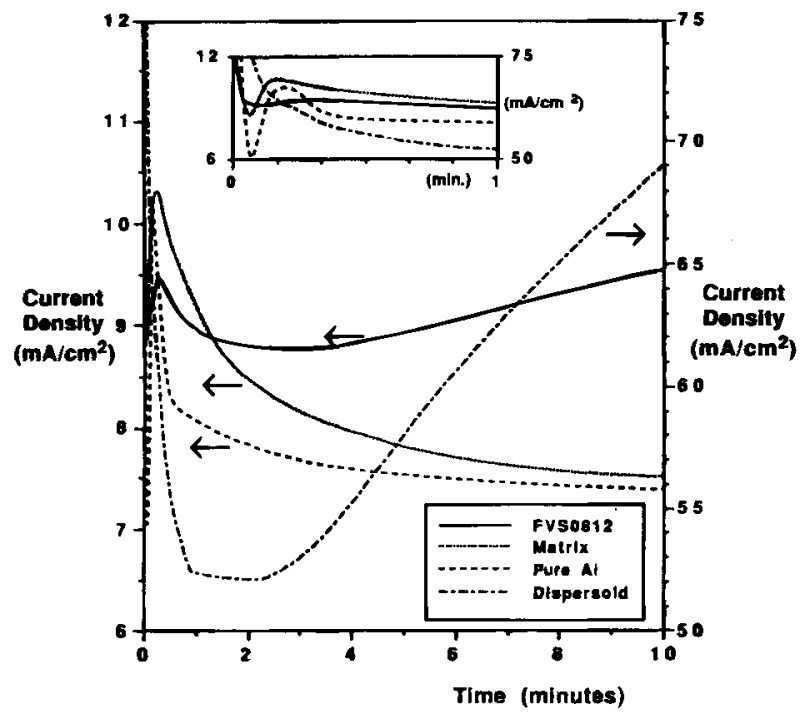

Fig. 2. Current density transients of pure Al, the matrix material, alloy FVSO812, and the dispersoid material during a hold at $10 \mathrm{~V}$ in $20^{\circ} \mathrm{C} 2.0 \mathrm{~mol} /$ liter sulfuric acid. The inset provides an enlarged view of the first minute. is quite similar to that of the pure $\mathrm{Al}$ with the appearance of a current minimum at ca. 5 to $10 \mathrm{~s}$ (inset, Fig. 2), followed by a current peak before the establishment of a slightly declining, almost steady-state current. These characteristic $i / t$ transients for both pure $\mathrm{Al}$ and the matrix suggest porous film formation. The initial drop in the transient corresponds to barrier layer thickening, the minimum corresponds to the onset of major pore development in the barrier layer, and the subsequent steady-state current corresponds to the establishment of the steadystate porous oxide growth due to the equilibrium between oxide formation and dissolution at the pores bases. ${ }^{18,19}$

In contrast, the current passed at the dispersoid during a hold at $+10 \mathrm{~V}$ in the acidic solution does not display the $i / t$ transient characteristic of porous oxide growth. However, the current passed at the dispersoid is significantly greater than that at the other substrates, and increases relatively rapidly with time, probably indicating surface roughening by dissolution of this substance in the acidic medium, borne out by solution analysis, in addition to the oxygen evolution that is observed visually. The initial seconds of the $i / t$ transient for the FVS0812 alloy is similar in profile to that of pure $\mathrm{Al}$ and the matrix material, exhibiting the current peak suggestive of porous film formation. However, similar to the dispersoid, the steadystate current is soon followed by a slight but continuous current increase. Thus the FVS0812 alloy displays the electrochemical behavior of both its component phases.

After $10 \mathrm{~min}$ at $10 \mathrm{~V}$, the current densities, based on the geometric areas, are ca. $7.5,7.5,9.5$, and $70 \mathrm{~mA} / \mathrm{cm}^{2}$ for pure Al, the matrix, alloy FVS0812, and the dispersoid, respectively, a ratio of ca. 1 to 1 to 1.5 to 9.5 . During the potential hold at $10 \mathrm{~V}$, copious evolution of gas occurred at the dispersoid, suggesting that any oxide formed on the intermetallic surface must contain a large number of flaws or must be much more conductive. Significant oxygen evolution at the FVS0812 surface, observed during the potential hold at $10 \mathrm{~V}$, compared to only a minor accumulation of gas bubbles at $\mathrm{Al}$ and the matrix surfaces under the same conditions, also contributes to the greater current response of the alloy, compared to pure $\mathrm{Al}$ and the matrix, and indicates that the alloy's oxide film is less protective and insulating than those of the other two substrates. The oxidation regime resulted in a darkening of the FVS0812 electrode surface, in contrast to that of pure $\mathrm{Al}$ and the matrix which supported a transparent oxide film.

For pure Al, the literature indicates that the thickness of the porous oxide film increases with time at constant potential. For example, the thickness of porous alumina formed at the current densities used in this work has been reported as reaching a limiting thickness of more than 20 $\mu \mathrm{m}{ }^{20}$ The relatively high magnitude of the current passed at the FVS0812 substrate compared to $\mathrm{Al}$, would suggest that at least an equivalent thickness of porous film should form on the alloy, yet in practice it was found that the maximum thickness of the oxide film formed on FVS 0812 under regular anodizing conditions was $3.5 \mu \mathrm{m} .{ }^{11}$ Thus, contributions to current arising from processes other than porous aluminum oxide formation must be more prevalent at the FVS0812 substrate than at pure $\mathrm{Al}$. In particular, the increasing currents at both the dispersoid and alloy FVS0812 suggest enhanced dissolution rates with consequent surface roughening.

Although much past work has been reported concerning porous Al oxide films, little literature exists in which the potentiodynamic technique has been used in studies of Al and its alloys in acidic solutions. ${ }^{21-26}$ As part of this initial comparison study, the matrix, dispersoid, and FVS0812 were studied by cyclic voltammetry (CV) in room temperature $2.0 \mathrm{~mol} / \mathrm{liter}$ sulfuric acid. Figure $3 \mathrm{a}, \mathrm{b}$, and $\mathrm{c}$ displays typical first and second cycle CVs of the bulk form of the matrix, alloy FVS0812, and the bulk form of the dispersoid, respectively, at $100 \mathrm{mV} / \mathrm{s}$. Al oxide films cannot be electrochemically reduced in this medium and hence only anodic CV profiles are of interest. These CVs display linearly increasing current with increasing potential. In con- 
trast, the CVs of Al-based materials at $100 \mathrm{mV} / \mathrm{s}$ in barrier film forming neutral solution show a constant current plateau during the initial anodic sweep, an abrupt drop in current upon potential reversal resulting in significantly reduced current on the cathodic sweep and almost no current on the second anodic sweep until potentials approaching the previous upper limit are achieved. ${ }^{21,25}$ Compared to neutral barrier film forming solution, the charge densities passed during one cycle of potential at $100 \mathrm{mV} / \mathrm{s}$ between potential limits of -1 and $10 \mathrm{~V}$ are much higher. The respective charge densities in neutral and acidic solution are 40 and $1050 \mathrm{mC} / \mathrm{cm}^{2}$ for the matrix material, 50 and $1250 \mathrm{mC} / \mathrm{cm}^{2}$ for alloy FVS0812, and 150 and $1500 \mathrm{mC} / \mathrm{cm}^{2}$ for the dispersoid material.

As shown in Fig. $3 \mathrm{a}$ and b, the CVs to $10 \mathrm{~V}$ of the matrix and FVS0812 are quite similar in profile. In this anodizing
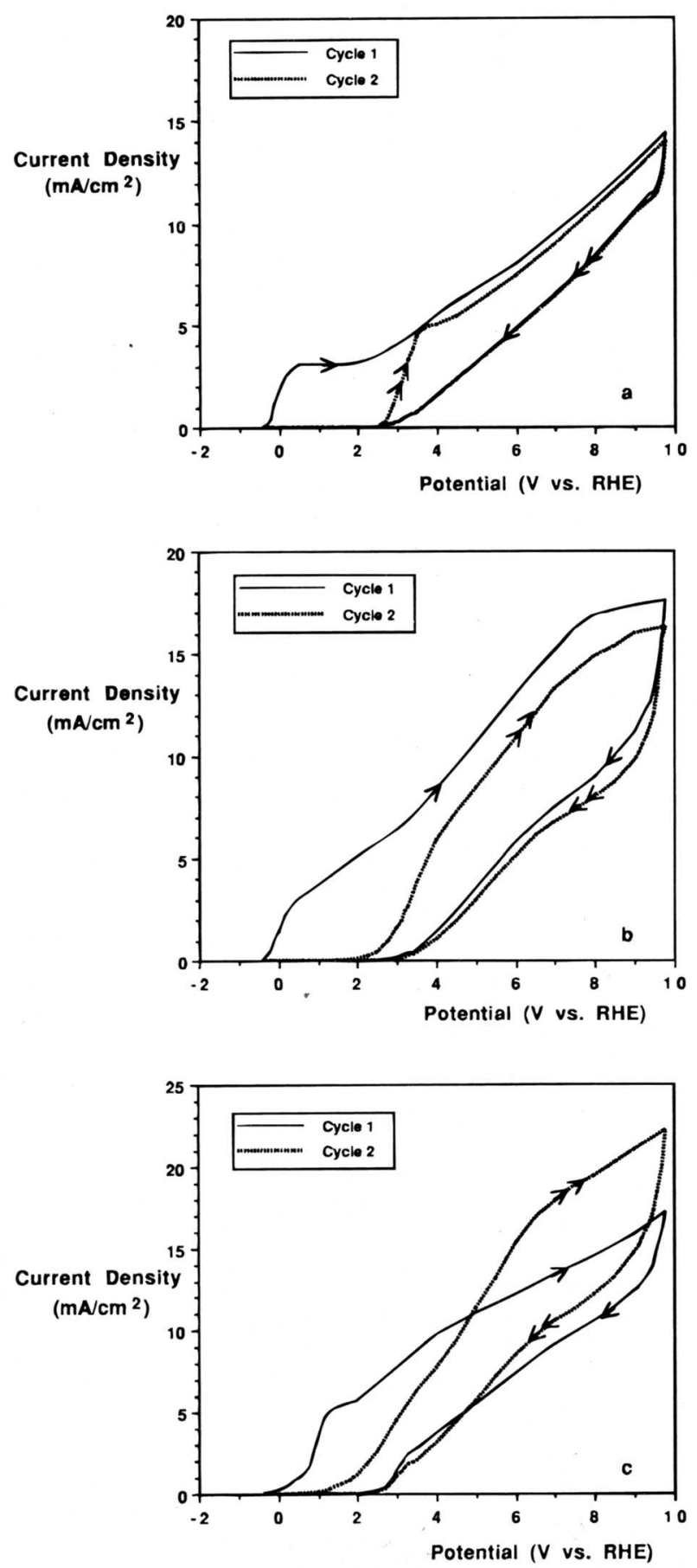

Fig. 3. Cyclic voltammograms of the substrates under study in $20^{\circ} \mathrm{C} 2.0 \mathrm{~mol} /$ liter sulfuric acid at a sweep rate of $100 \mathrm{mV} / \mathrm{s}$ : (a) matrix, (b) FVS0812, and (c) dispersoid. medium, FVS0812 has only a somewhat higher current density than the matrix (Fig. 3b vs. 3a). This result is somewhat unexpected because of the large volume fraction of the dispersoid phase, $c a .27 \mathrm{v} / \mathrm{o}$, in the alloy. Figure $3 \mathrm{c}$ confirms that the dispersoid displays the highest current in acidic solution. Surface roughening with repeated cycling was apparent from the increase of current with successive scans, in agreement with the results shown in Fig. 2 at constant potential. After cycling, the surface also showed significant roughening under an optical microscope. Due to the facile dissolution of the bulk dispersoid, minimal work could be performed in acidic solution with this material.

Oxide film formation in acidic solution is evidenced in Fig. $3 \mathrm{a}$ to $\mathrm{c}$ by the reduced current on the reverse sweep and the almost complete suppression of current at potentials below ca. 2.5, 2, and $1 \mathrm{~V}$ for the matrix, alloy, and dispersoid, respectively, on the second (and subsequent) anodic scans. This initially hindered second cycle current indicates the presence of some barrier oxide underlying the porous oxide, as the underlying barrier film would prevent significant current flow until a potential is achieved which is great enough such that the resulting field produces ionic and/or electronic migration through it. It is suggested that the onset of current above these potentials, e.g., $2.5 \mathrm{~V}$ in Fig. $3 \mathrm{a}$, indicates that the barrier oxide underlying the porous film formed in the first forward sweep in acidic solution has had sufficient time to partially dissolve during the reverse cycle. In contrast, the second anodic sweep in barrier film forming neutral solution does not show current flow until the prior upper potential limit is reached, as the barrier film is not soluble in neutral solution.

EDX/TEM examination of oxide films.-Figure 4 shows a micrograph of the extruded form of alloy FVS0812. The microstructure displays the very fine, nearly spherical $\mathrm{Al}_{13}(\mathrm{Fe}, \mathrm{V})_{3} \mathrm{Si}$ dispersoids, circular in shape with a light gray color, uniformly distributed throughout the matrix material, as reported by other researchers. ${ }^{1,5,7-9}$ The dispersoids have an average diameter of ca. $50 \mathrm{~nm}$. Individual matrix grains, varying in size from 500 to $1000 \mathrm{~nm}$, are too large to be defined within the micrograph. EDX analysis of alloys FVS0812 confirmed that the matrix phase was composed almost exclusively of $\mathrm{Al}$ while the dispersoid phase of the alloy contained Al, Fe, V, and Si (Table I).

The bulk matrix material and alloy FVS0812 were oxidized at $10 \mathrm{~V}$ for only $5 \mathrm{~min}$ in $2.0 \mathrm{~mol} / \mathrm{liter}$ sulfuric acid to allow sample preparation by ultramicrotomy and examination of the oxide cross sections by TEM. The micrographs of the oxide films formed on the matrix and FVS0812 in acidic solution show very different structures.

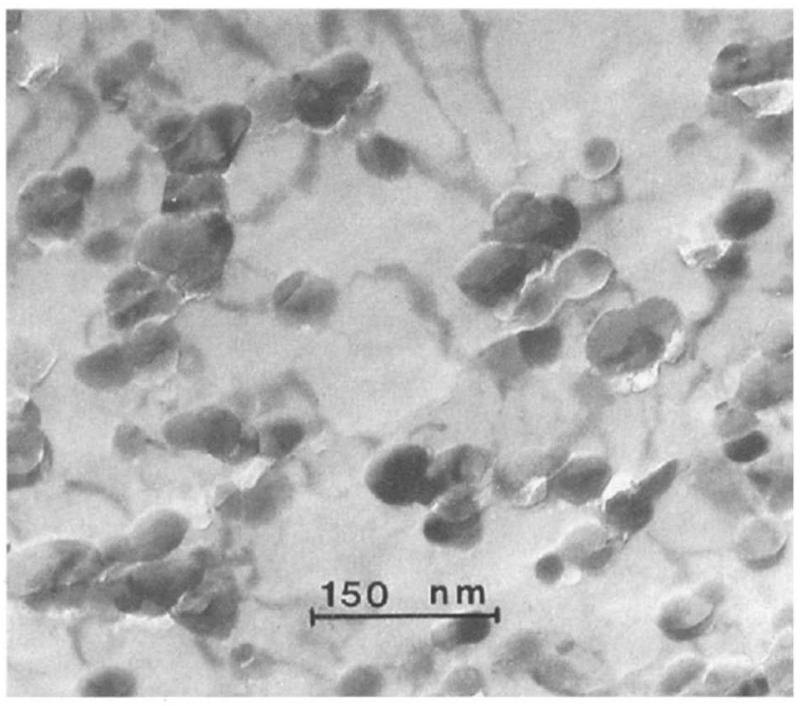

Fig. 4. TEM of alloy FVS0812. 
Figure 5a is a micrograph of the matrix covered by a classical porous anodic film with narrow cylindrical pores passing perpendicularly from the underlying barrier layer to the outer surface. The morphology, overall, is similar to that described in the literature for pure $\mathrm{Al}^{19,27-30}$ and the thickness of the porous component of the film, formed during $5 \mathrm{~min}$ of oxidation at $20^{\circ} \mathrm{C}$, is $c a, 1 \mu \mathrm{m}$, comparable to that reported in the literature for film formed on $\mathrm{Al}$ under similar conditions. ${ }^{20}$ These results are consistent with the similar $i / t$ and $\mathrm{CV}$ responses for pure $\mathrm{Al}$ and the matrix material.

Figure 5b is a micrograph of FVS0812 (lower left) supporting a film formed under the same experimental conditions as for the matrix, depicted in Fig. 5a. In contrast to the regular nature of the matrix porous oxide, the oxide film formed on FVS0812 is nonstructured in appearance. In contrast to the omnipresent underlying barrier layer at the base of the porous film formed on the matrix material, the barrier film at the interface between the alloy substrate and its porous oxide appears intermittent in nature. The porous film formed on FVS0812 is only $c a$. $70 \%$ the thickness of that formed on the matrix in the same time period, although Fig. 2 indicates that the charge density
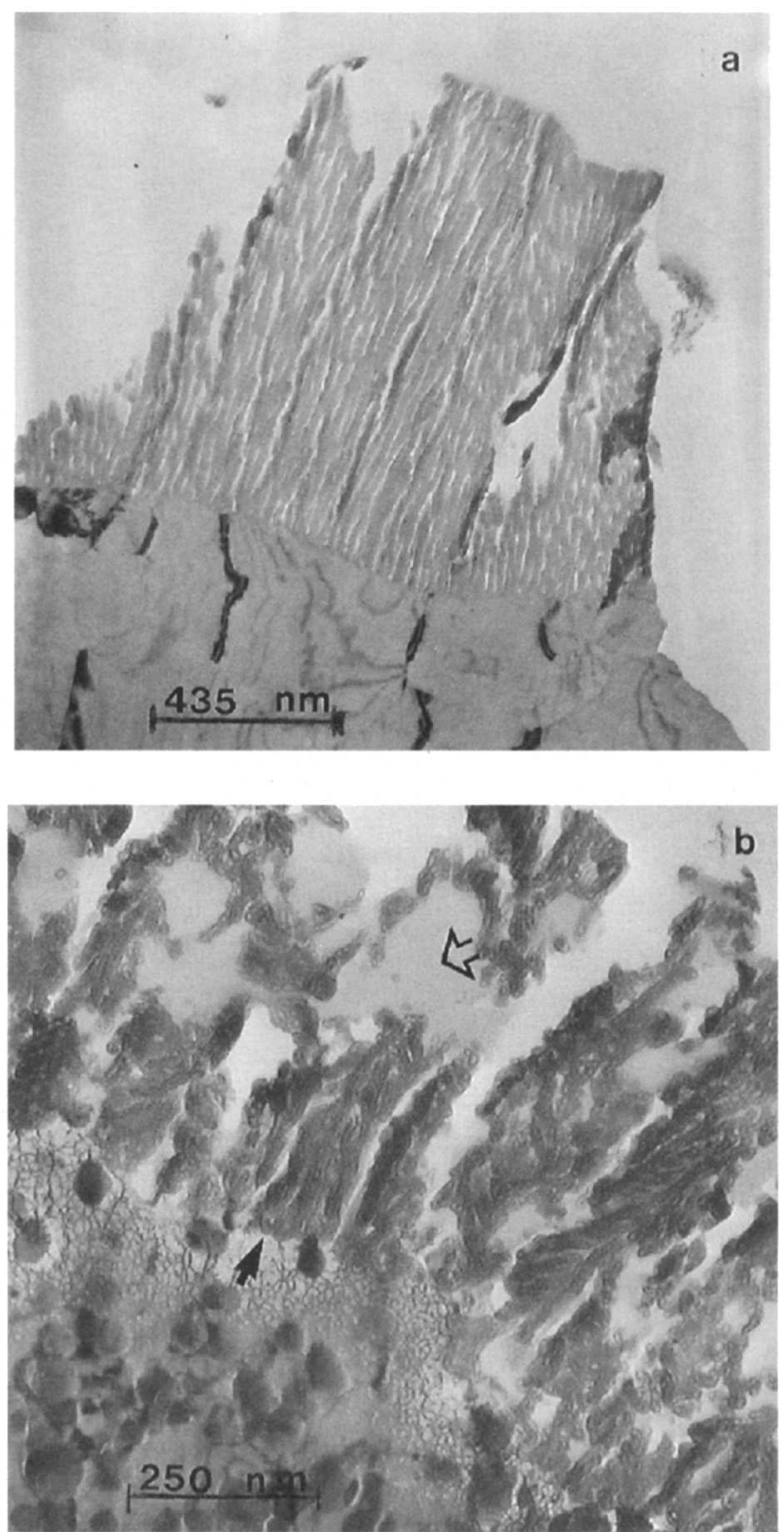

Fig. 5. TEM of oxide film formed on the substrates in $20^{\circ} \mathrm{C}$ $2.0 \mathrm{~mol} /$ liter sulfuric acid at $10 \mathrm{~V}$ (RHE) for $5 \mathrm{~min}$. Substrate at bottom, oxide in middle, resin at top. Closed arrow, barrier film. Open arrow, void (a) matrix and (b) FVS0812. passed by the alloy is somewhat greater than that passed by the matrix at the same potential and time. This decreased oxide film thickness of the alloy, with respect to the matrix, after only $5 \mathrm{~min}$ of anodization indicates the alloy's reduced ability to form a thick film under regular anodizing conditions.

A closer examination of the FVS0812 substrate/film interface reveals a very rough substrate surface. The lathing of the alloy surface during electrode surface preparation may have exacerbated the substrate roughening by the physical removal of surface dispersoids, aided by partial dissolution of the dispersoid phase from the alloy substrate. In contrast to the structured appearance of the matrix oxide and parallel nature of its pores (Fig. 5a), the oxide on the alloy (Fig. 5b) has a more contorted structure with the pores appearing to terminate or branch at random locations. Disorder in the porous oxide structure is also probably due to the presence, at the substrate/film interface, of dispersoids which alter the orientation of oxide growth as the surrounding matrix becomes oxidized.

Large voids are observed within the porous film formed on the FVS0812 surface. The voids are filled with embedding resin (Fig. 5b, top center) and thus were part of the oxide film and not an artifact of the sample preparation. The voids are roughly the same diameter as the spherical dispersoids, $c a .40 \mathrm{~nm}$. There does not appear to be any evidence of dispersoids within the porous oxide film on the alloy. These results suggest that the dispersoids are not completely electrochemically dissolved from the FVS0812 alloy surface, but rather become incorporated into the growing porous oxide film. With time, they would be susceptible to chemical dissolution, (as is seen by the dissolution of the bulk form of the dispersoid at open circuit in acidic solutions), and thus would be lost from the oxide film with time in solution. This would occur increasingly toward the outer part of the porous oxide films, as these sites would have been exposed to the acidic medium for longer time periods, thus weakening it substantially and leaving behind a very porous alumina structure. This could be the major reason why the oxide films do not exceed a limiting thickness of ca. $3.5 \mu \mathrm{m}$.

Solution analysis.-Sulfuric acid solutions in which identical oxidation programs involving alloy FVS0812 and the bulk forms of the matrix and the dispersoid were carried out were analyzed by ICP-AES for their Al, Fe, V, and Si content to establish the extent of substrate dissolution. Table II compares the concentration of the metals present after each substrate was in $20^{\circ} \mathrm{C} 2.0 \mathrm{~mol} /$ liter sulfuric acid under applied potential for a total of $\mathrm{ca} .45 \mathrm{~min}$, as opposed to the $5 \mathrm{~min}$ of oxidation for TEM analysis, to allow sufficient dissolution to occur to ensure detection of the metals.

The presence of $\mathrm{Al}$ in solutions in which the substrates were oxidized is expected as porous film formation in the acidic solution cannot occur without Al dissolution. ${ }^{19}$ The matrix phase of the alloy was reported to consist of $\mathrm{Al}$ supersaturated with 0.5 a/o $\mathrm{Fe}, \mathrm{ca} .0 .1 \mathrm{a} / \mathrm{o} \mathrm{Si}$, and no detectable $\mathrm{V}^{3}$ The presence of $\mathrm{V}$ in the solution after oxidation of the bulk form of the matrix (Table II) may be due

Table II. Al, Fe, V, and Si content of $20^{\circ} \mathrm{C} 2.0 \mathrm{~mol} /$ liter sulfuric acid solutions in which comparable oxidation programs were performed with the matrix, alloy FVS0812, and the dispersoid. (Normalized to $\mathrm{ppm} / \mathrm{cm}^{2}$ of electrode area.)

\begin{tabular}{|c|c|c|c|c|}
\hline \multirow[b]{2}{*}{ Substrate } & \multicolumn{4}{|c|}{ Concentration of element $\left(\mathrm{ppm} / \mathrm{cm}^{2}\right)$} \\
\hline & $\begin{array}{c}\mathrm{Al} \\
\left(\mathrm{LQD}^{\mathrm{a}} 0.08\right)\end{array}$ & $\begin{array}{c}\mathrm{Fe} \\
\left(\mathrm{LQD}^{\mathrm{a}} 0.01\right)\end{array}$ & $\begin{array}{c}\mathrm{V} \\
\left(\mathrm{LQD}^{\mathrm{a}} 0.02\right)\end{array}$ & $\begin{array}{c}\mathrm{Si} \\
\left(\mathrm{LQD}^{\mathrm{a}} 0.05\right)\end{array}$ \\
\hline Blank & ND & ND & ND & ND \\
\hline Matrix & 23 & 1.3 & 0.41 & 0.82 \\
\hline FVS0812 & 16 & 5.0 & 0.76 & 1.0 \\
\hline Dispersoid & 110 & 72 & 6.4 & 13 \\
\hline
\end{tabular}

\footnotetext{
${ }^{a}$ LQD refers to the lowest quantity detectable.
} 
to the incorporation of some $\mathrm{V}$ during production of the matrix material in bulk form. Fe, V, and Si are present in greater quantities in the solution in which FVS0812 was oxidized, compared to the solution in which the matrix was oxidized (Table II). As ca. $27 \%$ of the alloy consists of dispersoids, and as the dispersoid material is very prone to dissolution in $2.0 \mathrm{~mol} / \mathrm{liter}$ sulfuric acid, as indicated in Table II, the increased amount of $\mathrm{Fe}, \mathrm{V}$, and $\mathrm{Si}$ is consistent with the dissolution of the dispersoid phase from the FVS0812 alloy.

As indicated in Table III, the ratio, normalized to the V content, of the Fe, V, and $\mathrm{Si}$ in solution for the FVS0812 alloy and the bulk dispersoid phase reflects their weight percent in these two substrates. Therefore, it appears that some field-assisted dissolution of Fe, V, and Si occurs from the dispersoid phase of alloy FVS 0812 as it does from the dispersoid itself. In contrast, the amount of $\mathrm{Al}$ in solution for all substrates is less than expected, based on its content in the substrates. This retention of $\mathrm{Al}$ is consistent with the formation of aluminum oxide on all substrates, with more Al being retained in the form of an oxide on FVS0812 (68:22), probably reflecting the presence of the matrix component, compared with the dispersoid (28:18).

Efforts were made to bring together the observed film thickness on FVS0812 from TEM studies with the detected amount of dissolved metal in solution by ICP-AES and the total charge passed. However, a major problem in this analysis is that film thickness could only be legitimately examined after relatively short times of oxidation, e.g., $5 \mathrm{~min}$, as at longer times, a limiting oxide thickness would be encountered, ${ }^{11}$ while after 5 min of oxidation, the level of dissolved metal in solution was too low to be detected by ICP. Also, the large (but unknown) amount of oxygen evolved during anodization, as well as the difficulty in estimating the true amount of oxide film formed (due to uncertain film porosity) made the carrying out of even a semiquantitative mass balance calculation impossible.

Probing the barrier oxide layer with ac impedance.-It has been reported previously ${ }^{31,32}$ that the presence of a thin, unsealed porous oxide film on $\mathrm{Al}$ does not contribute to the total measured impedance, and that impedance measurements of such films therefore do not provide information about the pore structure or porous oxide film thickness. It has also been suggested ${ }^{33}$ that the contribution of the porous oxide film, unaltered by sealing, to the capacitive response can only be detected at frequencies exceeding $10^{7} \mathrm{~Hz}$. In the present work, the capacitive response of porous oxide films formed in 2.0 mol/liter sulfuric acid was used primarily as a probe of the barrier oxide layer underlying the porous film, as a strategy to determine if the instability and poor properties reported for the porous oxide film formed on alloy FVS0812 ${ }^{11}$ are related to the properties of the underlying barrier oxide.

The anodic oxide films were grown in $2.0 \mathrm{~mol} / \mathrm{liter}$ sulfuric acid by stepping the potential from open circuit to $10 \mathrm{~V}$ vs. a Pt CE and holding the potential at that value for either $5 \mathrm{~min}$, to form thin porous oxide films equivalent to the porous oxide films examined by TEM as described previously, or for $2.5 \mathrm{~h}$, to form thick porous oxide films. The porous oxide coated electrodes were then removed from the acidic solution, rinsed with triply distilled water, and equilibrated in $20^{\circ} \mathrm{C}$ neutral boric acid/sodium borate solution. The potential of the WE was held at $-0.14 \mathrm{~V}$ (SCE), a potential at which the neutral boric acid/sodium borate is nonaggresive to the substrates, while the impedance data were collected.

The values provided in Table IV for the $R$ and $C$ components after $5 \mathrm{~min}$ of anodization in sulfuric acid are based on the geometric areas of the respective WEs. The $C$ values are calculated from the constant phase elements $(C P E)$ and associated $n$ exponent of each of the films obtained from the data analysis using EQUIVALENT CIRCUIT Version 4.51 software by Boukamp. The term $C P E$ is used in recognition of the fact that, experimentally, dielectric films in electrochemical systems never exhibit the theoretically expected phase angle shift of $90^{\circ}$ for a capacitor, but rather a somewhat lower one. ${ }^{34}$ The $n$ exponent associated with a $C P E$ is an indication of the nonideality of the capacitive response. Strictly speaking, $C$ is equivalent to the $C P E$ of a film when $n=1$. The conversion of the $C P E$ of the film to $C$ is accomplished by the following equation ${ }^{35}$

$$
C=C P E \sin (n 90)
$$

Although the lowest value of the $n$ exponent which can be used in the above equation is somewhat arbitrary, $0.8<$ $n \leq 1$ has been suggested. ${ }^{35}$ For values of $n<0.8$, the CPE is converted to $C$ using the relationship ${ }^{35}$

$$
C=(C P E)^{n}
$$

Figure $6 a$ and $b$ shows the Bode diagrams illustrating the dependence of the total impedance and phase angle, respectively, on the ac frequency for thin oxide films formed for $5 \mathrm{~min}$ on the bulk matrix material, alloy FVS0812, and the bulk dispersoid material. These 5 min porous films have thicknesses of $c a .1 \mu \mathrm{m}$ at the matrix and $0.7 \mu \mathrm{m}$ at FVS0812, as shown in by TEM analyses (Fig. $5 \mathrm{a}$ and $\mathrm{b}$ ). The equivalent circuit that best fits the data obtained for the matrix and alloy materials is one with a

\begin{tabular}{|c|c|c|c|c|c|c|c|c|}
\hline & \multicolumn{2}{|c|}{ Matrix } & \multicolumn{3}{|c|}{ FVS 0812} & \multicolumn{3}{|c|}{ Dispersoid } \\
\hline & $\begin{array}{l}\text { w/o in } \\
\text { substrate }\end{array}$ & $\begin{array}{l}\text { Ratio } \\
\text { ppm in } \\
\text { solution }\end{array}$ & $\begin{array}{l}\text { W/o in } \\
\text { substrate }\end{array}$ & $\begin{array}{c}\text { Ratio } \\
\text { w/o in } \\
\text { substrate }\end{array}$ & $\begin{array}{l}\text { Ratio }^{a} \\
\text { ppm in } \\
\text { solution }\end{array}$ & $\begin{array}{l}\text { w/o in } \\
\text { substrate }\end{array}$ & $\begin{array}{c}\text { Ratio }^{\mathrm{a}} \\
\text { w/o in } \\
\text { substrate }\end{array}$ & $\begin{array}{l}\text { Ratio }^{\mathrm{a}} \\
\text { ppm in } \\
\text { solution }\end{array}$ \\
\hline $\begin{array}{l}\mathrm{Al} \\
\mathrm{Fe} \\
\mathrm{V} \\
\mathrm{Si}\end{array}$ & $\begin{array}{r}98.9 \\
1.0 \\
\text { ND } \\
0.1\end{array}$ & $\begin{array}{l}56 \\
3.2 \\
1 \\
2.0\end{array}$ & $\begin{array}{r}88.5 \\
8.5 \\
1.3 \\
1.7\end{array}$ & $\begin{array}{c}68 \\
6.5 \\
1 \\
1.3\end{array}$ & $\begin{array}{c}22 \\
6.5 \\
1 \\
1.4\end{array}$ & $\begin{array}{r}64.2 \\
27.8 \\
2.3 \\
5.7\end{array}$ & $\begin{array}{c}28 \\
12 \\
1 \\
2.5\end{array}$ & $\begin{array}{c}18 \\
11 \\
1 \\
2.0\end{array}$ \\
\hline
\end{tabular}

Table III. Comparison of ratios of Al, Fe, V, and Si content in solution to weight percent in substrate.

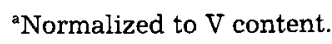

Table IV. Values of the components of equivalent circuits for oxide films formed on the matrix, alloy FVS0812, and the dispersoid in $2.0 \mathrm{~mol} /$ liter sulfuric acid at $10 \mathrm{~V}$ for $5 \mathrm{~min}$.

\begin{tabular}{lccccc}
\hline Substrate & $\begin{array}{c}R_{1} \\
\left(\Omega \mathrm{cm}^{2}\right)\end{array}$ & $\begin{array}{c}C_{1}^{* a} \\
(\mathrm{~F} \mathrm{~cm})\end{array}$ & $n_{1}$ & $\begin{array}{c}R_{2} \\
\left(\Omega \mathrm{cm}^{2}\right)\end{array}$ & $\begin{array}{c}C_{2}{ }^{2} \\
(\mathrm{~F} \mathrm{~cm})\end{array}$ \\
\hline Matrix & $5.5 \times 10^{4}$ & $2.1 \times 10^{-6}$ & 0.88 & & \\
FVS0812 & $3.3 \times 10^{4}$ & $2.2 \times 10^{-6}$ & 0.95 & $6.5 \times 10^{3}$ & $4.7 \times 10^{-3}$ \\
Dispersoid & $1.9 \times 10^{2}$ & $7.0 \times 10^{-4}$ & 0.75 & 0.65 \\
\hline
\end{tabular}

\footnotetext{
${ }^{a} \mathrm{C}$ is calculated from $\mathrm{CPE}$ and $n$ using Eq. 1 or 2.
} 
single $R C$ time constant, consisting of a parallel combination of the oxide $R$ and $C$, in series with the solution resistance $\left(R_{\mathrm{sol}}\right)$. In contrast, the equivalent circuit for the dispersoid material suggests the presence of two time constants, with a second parallel $R$ and $C$ combination in series with the first. The fact that only one time constant is seen for both the matrix material and alloy FVS0812 is in agreement with the Al literature for thin porous oxide films and indicates that the porous film is transparent by impedance measurements under these conditions. In the case of the dispersoid, the second time constant may reflect the porous component of the oxide formed on the dispersoid and/or the roughness of the substrate itself, confirmed by the significant roughening which developed during oxidation in the acidic solution.

It is seen in Table IV that both the matrix and the alloy yield very similar $R_{1}$ and $C_{1}$ values, with the capacitance of ca. $2.15 \times 10^{-6} \mathrm{~F} / \mathrm{cm}^{2}$ also being very close to that of a purely barrier film formed in neutral borate solution to the same potential on the matrix material, $1.9 \times 10^{-6} \mathrm{~F} / \mathrm{cm}^{2}{ }^{36}$ As $C$ is inversely proportional to the thickness of a nonconducting dielectric film, this suggests, first, a similar composition and thickness of the barrier oxides formed beneath the porous films on the matrix and FVS0812 alloy Second, consistent with the literature, ${ }^{27,30}$ this indicates that the barrier oxide formed in porous film forming acidic solution on the matrix is slightly thinner than that formed in neutral solution at the same potential. The $R$ values, which reflect the resistance of the film as well as
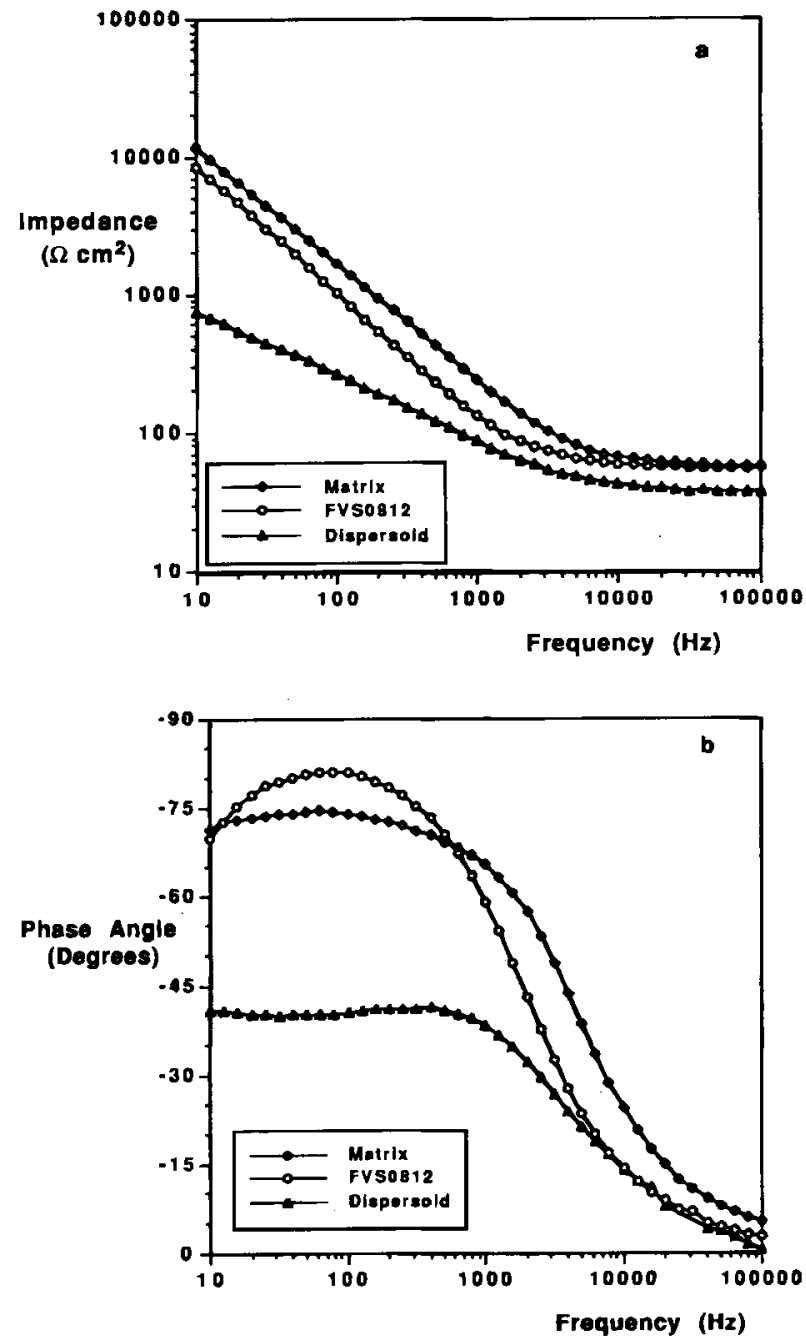

Fig. 6. Frequency dependence of (a) total impedance and (b) phase angle of oxide films formed on the matrix, FVS08 12 and dispersoid in $20^{\circ} \mathrm{C} 2.0 \mathrm{~mol} /$ liter sulfuric acid at $10 \mathrm{~V}$ (Pt) for $5 \mathrm{~min}$. the inverse of the rate of any redox reactions which can occur at the potential used for impedance measurements, are also very similar for these two materials; this is also demonstrated by the similarity of the $R_{1} C_{1}$ time constants. It is also of interest that the $n_{1}$ values associated with $C P E_{1}$, and used to calculate $C_{1}$, were in the range of 0.9 to 0.95 for these two materials. Values for $n$ which are less than unity can be an indication of impedance signatures arising from inside a porous conducting structure. (It is notable that the $n$ values for barrier films formed on pure $\mathrm{Al}$ in borate solutions are ca. $0.98{ }^{36}$ ) Overall, the matrix and the FVS0812 alloy appear to be almost indistinguishable by their impedance responses after only $5 \mathrm{~min}$ of porous oxide film formation, suggesting that the properties of both the barrier and porous oxide films are very similar, as indicated also by the $i / t$ and $C V$ data described earlier.

The impedance data for the 5 min anodized dispersoid are clearly quite different from those for the matrix and FVS0812 (Table IV). Based on the similarity of the calculated time constant for the first $R C$ pair, $R_{1} C_{1}$, to that for the matrix and FVS0812 alloy, $R_{1}$ and $C_{1}$ are assigned to a barrier oxide film. The comparatively high value of the capacitance, $C_{1}$, could be indicative of either the very high surface area which can clearly be seen to develop on the dispersoid even after only $5 \mathrm{~min}$ of anodization, or an extremely thin barrier oxide layer. By comparing $C_{1}$ of the dispersoid to that of either the matrix or the FVS0812 alloy, a very large roughness factor of $c a .325$ or a barrier oxide that is 325 times thinner than that on the matrix and alloy would then be indicated. As both of these possibilities seem to be unreasonable, it is more likely that the thin barrier film on the roughened dispersoid is also flawed and cracked, which could also contribute significantly to the increase in capacitance (and thereby reduce its resistance), as is indicated in Table IV. The second time constant, $\mathrm{R}_{2} C_{2}$, which is a new feature vs. the impedance response of the matrix and alloy, is quite different from that of the barrier film, i.e., ca. 230 times larger. It is suggested that the $R_{2} / C_{2}$ pair reflects the response of the porous structure of the etched dispersoid. It is notable that both $n_{1}$ and $n_{2}$ are in the range of 0.65 to 0.75 for the dispersoid, consistent with both of the signals coming from within a porous structure.

As the difficulties that had been found to exist in forming a strong, thick porous oxide film on the FVS0812 alloy surface $^{11}$ occurred with anodization times much greater than $5 \mathrm{~min}$, the substrates were again anodized in $2.0 \mathrm{~mol} / \mathrm{liter}$ sulfuric acid at $10 \mathrm{~V} v$ s. a $\mathrm{Pt} \mathrm{CE}$, but for $2.5 \mathrm{~h}$. Figure $7 \mathrm{a}$ and $b$ shows the Bode plots of the oxide films formed on the three substrates under these conditions. The thickness of the porous film formed on the matrix is estimated from the literature for $\mathrm{Al}^{20}$ to have reached its limiting value of ca. $20 \mu \mathrm{m}$. As summarized in Table $\mathrm{V}$, for these thick porous films, the best fit equivalent circuit for all substrates involves two time constants, with two parallel combinations of $R$ and $C$ in series with each other and with $R_{\text {sol }} \cdot R_{1}$ and $C_{1}$ are again suggested to reflect the barrier film at the base of the pores of the outer oxide in the case of the matrix and FVS0812, based largely on the similarities in the values of $C_{1}$ with those assigned to the barrier film in Table IV. However, after $2.5 \mathrm{~h}$ of anodization, $\mathrm{C}_{1}$ for the FVS0812 barrier film is ca. one and one-half to two times larger than $C_{1}$ for the matrix, with a corresponding drop in resistance. This suggests that, with longer times of anodization, either the barrier film is thinner on the FVS0812 alloy $v s$. the matrix, or that the barrier film on the FVS0812 alloy is flawed in certain locations, such that the intact part of the barrier oxide is thinner than expected. For these two substrates, the $n_{1}$ value is $c a$. 0.9 , suggestive of a barrier film being underneath the porous oxide film. A second time constant is now seen for both the matrix and the alloy, reflective of the presence of a thick, porous oxide film after $2.5 \mathrm{~h}$ of oxidation. It is notable that the $n_{2}$ values are only ca. 0.5 to 0.7 , indicative of a highly porous structure. Also, $R_{2}$ for the FVS0812 

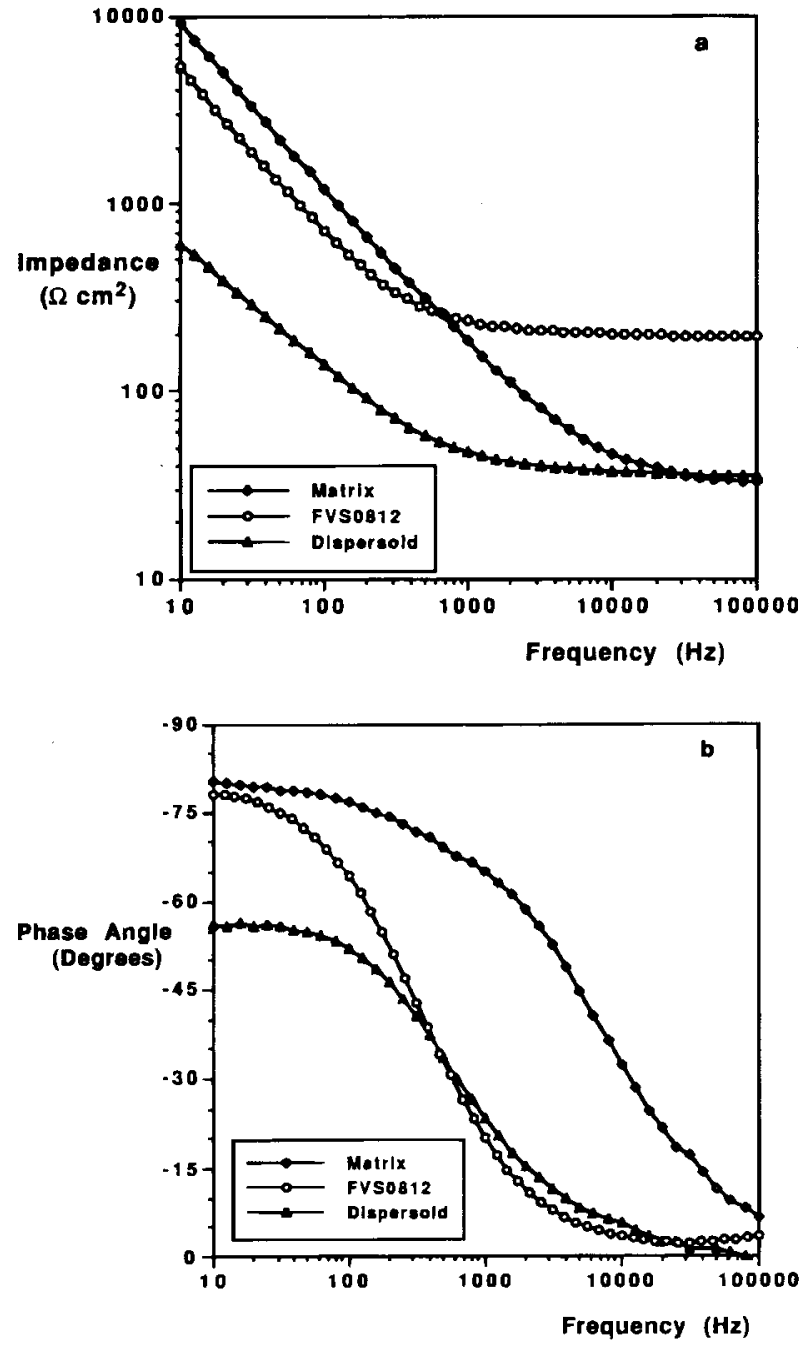

Fig. 7. Frequency dependence of (a) total impedance and (b) phase angle of oxide films formed on the matrix, FVSO812, and dispersoid in $20^{\circ} \mathrm{C} 2.0 \mathrm{~mol} /$ liter sulfuric acid at $10 \mathrm{~V}(\mathrm{Pt})$ for $2.5 \mathrm{~h}$.

alloy is ca. five times lower than $R_{2}$ for the matrix, suggesting that the porous oxide film itself is $c a$. five times thinner, or otherwise less resistive, on FVS0812 vs. the matrix.

The impedance data for the dispersoid after $2.5 \mathrm{~h}$ of oxidation (Table V) are very similar to that in Table IV for the dispersoid after only $5 \mathrm{~min}$ of anodization. The $n_{1}$ and $n_{2}$ values are both close to 0.75 to 0.8 , and the other components all appear to be essentially independent of the time of oxidation. It would have been expected that the roughness of the surface would have increased further with longer times of anodization and hence $C_{1}$ should be larger and $R_{1}$ correspondingly smaller. However, the impedance data are not consistent with this.

\section{Summary}

Electrochemical studies involving cyclic voltammetry, chronoamperometry, and impedance techniques were used to investigate the FVS0812 alloy and its two component phases. Significantly more charge density was passed at bulk dispersoid material than at the FVS0812 alloy which, in turn, passed more than the matrix material and pure $\mathrm{Al}$. $C V$ and $i / t$ techniques do not significantly differentiate between the oxide films formed on FVS0812 and its matrix phase in $2.0 \mathrm{~mol} / \mathrm{liter}$ sulfuric acid, although the growth of porous oxide films on these substrates is indicated and evidence of the electrochemical signature of both the matrix and dispersoid is seen within the FVS0812 alloy. The differences in the oxide films formed on the matrix and alloy FVS0812 as determined by EIS become more evident at long oxidation times. Compared to the matrix, the barrier layer on FVS0812 becomes less resistive, i.e., thinner or more defective, and the porous part of the film is significantly less resistive also.

TEM investigations confirmed that the barrier film underlying the porous film is continuous at the matrix substrate, in contrast to the underlying barrier film on FVS0812 which is intermittent in nature. Porous film formed on the matrix material has a classical appearance, with regular pores extending perpendicularly from the underlying barrier layer to the surface. Porous film formed on FVS0812 under the same conditions as on the matrix has a distorted appearance. This disordered structure is considered to be due, in part, to the presence of the dispersoid phase which alters the orientation of oxide growth as the matrix surrounding the spherical dispersoids becomes oxidized. Dispersoids are absent in the FVS0812 alloy's porous film. The large voids in the porous film, as indicated by TEM, provide evidence that the dispersoids are incorporated, perhaps somewhat oxidized, into the growing porous oxide film. With time in the acidic medium, the chemical dissolution of the dispersoids, with their concomitant loosening from within the oxide, results in holes and flaws in the porous film, which would significantly weaken the structure. The resulting fragility of the film would be more extensive toward the outer surface of the film, as the length of time of contact of dispersoids with the acid would be greater. This would lead to a weakened outer film surface, which could either break off, or simply dissolve with time, as it might be expected that low density, high surface area alumina would be even more prone to dissolution in the acidic medium. Thus, it is understandable that the thickness of the more fragile film on FVS0812 is limited. After 5 min of oxidation the film thickness on FVS0812 (ca. $0.7 \mu \mathrm{m}$ ) is only about $70 \%$ of the thickness of the film formed on the matrix material under identical conditions, a precursor to the limiting thickness of $c a .3 .5 \mu \mathrm{m}$ found on FVS0812 in practice.

\section{Acknowledgments}

Acknowledgment is made to Allied Signal Incorporated for providing the FVS0812 alloy, matrix, and dispersoid samples; Don Steele and David Tessier of Alcan International Limited, Kingston Research and Development Center, for assistance and instruction in the techniques of ultramicrotomy and transmission electron microscopy, and Dr. Petr Vanysek of Northern Illinois University for his assistance with the impedance experiments. Financial assistance to V.I.B. and S.C.T. from the Natural Sciences and Engineering Council of Canada, and to S.C.T. from the Alberta Heritage Scholarship Fund, the Canadian Federation of University Women, the Izaak Walton Killam Memorial Scholarship Fund, the University

Table V. Values of the components of equivalent circuits for oxide films formed on the matrix, alloy FVS0812, and the dispersoid in $2.0 \mathrm{~mol} /$ liter sulfuric acid at $10 \mathrm{~V}$ for $2.5 \mathrm{~h}$.

\begin{tabular}{|c|c|c|c|c|c|c|}
\hline Substrate & $\begin{array}{c}R_{1} \\
\left(\Omega \mathrm{cm}^{2}\right)\end{array}$ & $\left(\begin{array}{c}\mathrm{C}_{\mathrm{l}}^{\mathrm{a}} \\
\left(\mathrm{cm}^{-2}\right)\end{array}\right.$ & $n_{1}$ & $\begin{array}{c}R_{2} \\
\left(\Omega \mathrm{cm}^{2}\right)\end{array}$ & $\begin{array}{c}C_{2}{ }^{* a} \\
\left(\mathrm{~F} \mathrm{~cm}^{-2}\right)\end{array}$ & $n_{2}$ \\
\hline Matrix & $4.3 \times 10^{5}$ & $2.5 \times 10^{-6}$ & 0.91 & $1.1 \times 10^{2}$ & $2.0 \times 10^{-3}$ & 0.69 \\
\hline Dispersoid & $2.1 \times 10^{2}$ & $3.2 \times 10^{-4}$ & $0.7 \overline{9}$ & $1.1 \times 10^{4}$ & $1.3 \times 10^{-3}$ & 0.76 \\
\hline
\end{tabular}

\footnotetext{
${ }^{\mathrm{a}} \mathrm{C}$ is calculated from $C P E$ and $n$ using Eq. 1 or 2.
} 
of Calgary Faculty of Graduate Studies, the University of Calgary Department of Chemistry, and A. S. M. International "Calgary Chapter," is also gratefully acknowiedged.

Manuscript submitted April 1, 1996; revised manuscript received Oct. 14, 1996.

The University of Calgary assisted in meeting the publication costs of this article.

\section{REFERENCES}

1. S. K. Das and L. A. Davis, Mater. Sci. Eng., 98, 1 (1988).

2. S. K. Das, R. L. Bye, and P. S. Gilman, ibid., A134, 1103 (1991).

3. D. J. Skinner, M. S. Zedalis, and J. Peltier, in Light Weight Alloys for Aerospace Applications, E. W. Lee, E. H. Chia, and N. J. Kim, Editors, p. 71, The Minerals, Metals \& Materials Society, Warrendale, PA (1989).

4. P. Gilman, Met. Mater, 504 (1990).

5. D. J. Skinner, R. L. Bye, D. Raybould, A. M. Brown, and M. S. Zedalis, in Processing of Structural Metals by Rapid Solidification, Proceedings of a Seven Session Symposium on Enhanced Properties in Structural Metals via Rapid Solidification, p. 291, ASM International, Metals Park, Ohio (1987).

6. D. J. Skinner, M. S. Zedalis, and P. Gilman, Mater. Sci. Eng., A119, 81 (1989).

7. D. J. Skinner, R. L. Bye, D. Raybould, and A. M. Brown, Scr. Metall., 20, 867 (1986)

8. S. K. Das, J. Powder Metall., 24, 175 (1988)

9. D. J. Skinner, in Dispersion Strengthened Aluminum Alloys, Y.-W. Kim and W. M. Griffith, Editors, p. 181, The Mineral, Metals \& Materials Society, Warrendale, PA (1988).

10. D. Pletcher and F. Walsh, Industrial Electrochemistry, Chapman and Hall, London (1990).

11. V. I. Birss, Internal Report, Allied-Signal Inc., Morristown, NJ (1990)

12. R. Rateick, Personal communication, Allied-Signal Aerospace Company, Bendix Engine Controls Division (1991).

13. J. Timm, Key Eng. Mater, 44\&45, 219 (1990).

14. J. Zahavi, A. Zangvil, and M. Metzger, This Journal, 125,438 (1987)

15. K. Shimizu, G. E. Thompson, G. C. Wood, and K. Kobayashi, J. Mater. Sci. Lett., 10, 709 (1991).

16. H. S. Kim, G. E. Thompson, G. C. Wood, I. G. Wright, and R. E. Maringer in Proceedings of International Congress on Metal Corrossion, p. 659 (1984).

17. D. J. Skinner, Personal communication, 1993.

18. G. W. Wood and J. P. O'Sullivan, Electrochim. Acta., 15,1865 (1970).

19. G. E. Thompson and G. C. Wood, in Treatise on Materials Science and Technology, Vol. 23, J. C. Scully, Editor, Academic Press, Inc., New York (1983).

20. G. Patermarakis, P. Lenas, Ch. Karavassilis, and G. Papayiannis, Electrochim. Acta, 36, 709 (1991).

21. P. Ll. Cabot, J. A. Garrido, E. Perez, and J. Virgili, Corros. Sci, 26, 357 (1986).

22. P. L. Cabot, F. A. Centellas, J. A. Garrido, and E. Pérez, J. Appl. Electrochem., 17, 104 (1987).

23. P. Ll. Cabot, F. A. Centellas, J. A. Garrido, and E. Pérez, ibid., 17, 807 (1987).

24. S. C. Thomas and V. I. Birss, in Corrosion, Electrochemistry, and Catalysis of Metastable Metals and Intermetallics, C. R. Clayton and $\mathrm{K}$. Hashimoto, Editors, PV 93-30, p. 38, The Electrochemical Society Proceedings Series, Pennington, NJ (1993).

25. V. I. Birss, S. C. Thomas, and A. J. Zhang, Electrochim. Acta, 40, 1551 (1995).

26. S. C. Thomas, V. I. Birss, D. Steele, and D. Tessier, Microsc. Res. Tech., 31, 285 (1995).

27. J. P. O'Sullivan and G. C. Wood, Proc. R. Soc. London A., 317, $511(1970)$.

28. I. Farnan, R. Dupree, Y. Jeong, G. E. Thompson, G. C Wood, and A. J. Forty, Thin Solid Films, 173, 209 (1989).

29. Y. Fukuda, T. Fukushima, and M. Nagayama, Trans. Nat. Res. Ins. Met., 32, 29 (1990).

30. H. Terryn, J. Vereecken, and J. Landuyt, ibid., 68, 33 (1990).

31. B. van der Linden, H. Terryn, and J. Vereecken, $J$. Appl. Electrochem., 20, 798 (1990).

32. J. De Laet, J. Scheers, H. Terryn, and J. Vereecken, Electrochim. Acta, 38, 2103 (1993).

33. F. Mansfeld and M. W. Kendig, This Journal, 135, 828 (1988).

34. J. De Laet, H. Terryn, and J. Vereecken, Electrochim. Acta, 41, 1155 (1996).

35. P. Vanysek, Introduction to Electrochemical Impedance, The University of Calgary, Calgary, Alberta, Canada (1994).

36. S. C. Thomas and V. I. Birss, This Journal, 144, 558 (1997). 